\title{
PROGRAMA DE AQUISIÇÃO DE ALIMENTOS: LIMITES E POTENCIALIDADES DE POLÍTI- CAS DE SEGURANÇA ALIMENTAR PARA A AGRICULTURA FAMILIAR
}

\section{Programa de Aquisição de Alimentos (Brazil): limits and potentialities of food safety policies for family agriculture}

\author{
Rosângela Aparecida de Medeiros Hespanhol \\ Professora dos Cursos de Graduação e Pós-graduação em Geografia \\ Universidade Estadual Paulista (UNESP), Presidente Prudente, São Paulo, Brasil \\ rosangel@fct.unesp.br
}

Artigo recebido em 04/05/2013 e aceito para publicação em 29/05/2013

RESUMO: O Programa de Aquisição de Alimentos (PAA) foi criado no governo Lula (2003) como parte do Fome Zero. Esse programa tem como objetivo assegurar o acesso aos alimentos por pessoas que vivem em situação de insegurança alimentar e/ou nutricional e fortalecer a agricultura familiar, por meio de compras governamentais de alimentos. Considerando a importância do PAA como uma política diferenciada que nos detivemos na análise, tanto da sua implementação em escala nacional, como da sua operacionalização num contexto específico, tendo como recorte espacial o Município de Dracena, localizado na porção oeste do estado de São Paulo. Constatou-se que, tanto em escala nacional como municipal, o programa apresentou crescimento do número de projetos aprovados, produtores participantes, entidades beneficiadas e valores dos recursos. Entretanto, mesmo com essa expansão, a abrangência do PAA ainda é muito limitada e, ao mesmo tempo, concentrada em termos espaciais.

Palavras-chave: Políticas. Segurança alimentar. Programa de Aquisição de Alimentos. Agricultura familiar.

ABSTRACT: The Programa de Aquisição de Alimentos was created by the Lula administration (2003) as part of "Fome Zero" (Zero Hungry). This program aims to ensure access to food for people living in food and/or nutritional insecure situation and strengthen family agriculture, by food that is pushased by the government. Considering the importance of this program as a differentiated policy that we abode in the analysis far of its implementation on national scale, as its operationalization in a specific context, with the spatial cutout of the municipality "Dracena", located on São Paulo state western portion. It was found that, either in national and municipal levels, the program presented a growth on the number of approved projects, participating producers, benefited institutions and resource values. However, even with such expansion, the scope of this program is still quite limited and at the same time, too concentrated in spatial terms. Keywords: Public Policies. Food Safety. Programa de Aquisição de Alimentos. Family Agriculture. 


\section{INTRODUÇÃO}

Entre meados dos anos 1990 e início deste século (XXI), as políticas direcionadas ao meio rural brasileiro, particularmente as destinadas à agricultura de pequeno porte, passaram por importantes mudanças engendradas pelo Estado brasileiro.

No bojo das discussões que levaram a essas mudanças, duas temáticas ganharam relevância. A primeira relacionou-se à segurança alimentar e nutricional que, desde o final da década de 1980 e, sobretudo no início dos anos 1990, por meio da Campanha "Ação da Cidadania contra a Fome, a Miséria e pela Vida", recolocou para a sociedade e o Estado a necessidade de ações políticas visando retirar da miséria e da fome milhões de brasileiros. Essa problemática ganhou mais espaço no governo federal a partir de 2003, com a eleição do presidente Luís Inácio Lula da Silva e a criação do Fome Zero. A segunda temática diz respeito ao reconhecimento por parte do Estado brasileiro da importância econômica e social que a agricultura familiar desempenha no país. Esse reconhecimento se deu, desde 1996, por meio da implementação do Programa Nacional de Fortalecimento da Agricultura Familiar (PRONAF).

Com o objetivo de assegurar o acesso aos alimentos às entidades assistenciais que atendem pessoas que vivem em situação de insegurança alimentar e/ou nutricional e fortalecer a agricultura familiar foi criado, no âmbito do Fome Zero, o Programa de Aquisição de Alimentos (PAA).

Tendo em vista a importância que esse programa pode desempenhar como uma política diferenciada que nos detivemos na análise, tanto da sua implementação em escala nacional, como da sua operacionalização num contexto específico, tendo como recorte espacial o Município de Dracena, localizado na porção oeste do estado de São Paulo.

Para atingir esse objetivo realizamos levantamento bibliográfico sobre a temática abordada; coleta e análise de dados de fonte secundária, como no Escritório de Desenvolvimento Rural de Dracena (EDR) e acesso a sites oficiais, como do IBGE (Censos Agropecuários e Demográficos, Produção Agrícola Municipal etc.), Ministério do Desenvolvimento Social e Combate à Fome (MDS), Ministério do Desenvolvimento Agrário (MDA), Companhia Nacional de Abastecimento (CONAB), entre outros; e, pesquisa de campo no Município de Dracena (SP), com a aplicação de formulários semiestruturados a 19 produtores rurais participantes do programa e os responsáveis por 16 instituições da rede socioassistencial que eram atendidas no ano de 2010.

O presente artigo esta estruturado, além desta introdução, das considerações finais e das referencias, em três partes. Na primeira parte se abordou a estruturação do PAA, seus objetivos e modalidades, bem como sua evolução no país no período 2003 a 2011. Na segunda parte, se priorizou o contexto socioeconômico do município de Dracena, a crise da cafeicultura e as alternativas buscadas pelos produtores rurais para se manterem no campo. A partir desse contexto, na terceira e última parte, se analisou, o desempenho do PAA no Município de Dracena, analisando os limites e as possibilidades dessa política pública como estratégia de reprodução social dos agricultores familiares.

\section{O PROGRAMA DE AQUISIÇÃO DE ALIMEN- TOS - PAA}

O Programa de Aquisição de Alimentos - PAA foi criado em julho de 2003, por meio do artigo $19 \mathrm{da}$ lei $\mathrm{n}^{\circ} 10.696$. Esse programa possui duas finalidades principais: promover o acesso à alimentação e incentivar a agricultura familiar. Para alcançar esses dois objetivos, o programa compra alimentos produzidos pela agricultura familiar, com dispensa de licitação, e os destina às pessoas em situação de insegurança alimentar e nutricional atendidas pela rede socioassistencial, pelos equipamentos públicos de segurança alimentar e nutricional e pela rede pública e filantrópica de ensino (MDA, 2012).

O PAA também contribui para a constituição de estoques públicos de alimentos produzidos pelos agricultores familiares. Além disso, o programa promove o abastecimento alimentar por meio de compras governamentais de alimentos; fortalece circuitos locais e regionais e redes de comercialização; valoriza a biodiversidade e a produção orgânica e agroecológica de alimentos; incentiva hábitos alimentares saudáveis e estimula o cooperativismo e o associativismo (MDA, 2012). 
Para participar do programa, os produtores rurais devem apresentar a Declaração de Aptidão do PRONAF (DAP) e, preferencialmente, estarem organizados em cooperativas, associações ou grupos de interesse informais com, no mínimo, cinco agricultores.

O Programa funciona de maneira a adquirir alimentos produzidos pelos agricultores familiares a preços baseados na cotação do mercado regional e fornecê-los às entidades da rede socioassistencial. De acordo com Mattei (2007, p. 5), "os instrumentos do programa beneficiam tanto o agricultor familiar como os consumidores [...]. Desta forma, busca-se uma associação entre a política de segurança alimentar e nutricional e as políticas de promoção da agricultura familiar".

Para Maluf (2001), a criação do PAA tem como objetivo romper com o círculo vicioso da fome, provocado pela falta de políticas que criem novas oportunidades de emprego e renda, evidenciando assim uma forma integrada de se pensar tanto as políticas sociais como aquelas destinadas à agricultura, já que privilegia a agricultura familiar. Isso porque, viabilizar "a produção agro-alimentar é, ao mesmo tempo, enfrentar a pobreza rural e um dos principais focos de insegurança alimentar" (MALUF, 2001, p. 166).

Uma característica marcante do programa é sua flexibilidade, adaptando-se às especificidades regionais, por isso encontra-se em constante (re) formulação desde sua implantação no Plano Safra de 2003/2004. O PAA tem sido aprimorado no seu arcabouço jurídico-institucional, no modo de operação e de suas modalidades, parcerias e as fontes de recursos envolvidas (PORTO, 2009).

Em termos institucionais, o PAA tem sido acompanhado em sua trajetória de formulação e implementação pelo Conselho de Segurança Alimentar (CONSEA) e por diferentes organizações da sociedade civil. Em âmbito nacional, o programa é coordenado por um Grupo Gestor que envolve representantes dos seguintes ministérios: Desenvolvimento Social e Combate à Fome (MDS); Planejamento, Orçamento e Gestão; Desenvolvimento Agrário (MDA); Agricultura, Pecuária e Abastecimento (MAPA); Fazenda; e, mais recentemente, do Ministério da Educação. A parte operacional do programa está a cargo do MDS e da CONAB.
As ações do PAA são operacionalizadas por meio do estabelecimento de convênios entre o MDS e as administrações estaduais e municipais. No caso dos convênios com os governos estaduais, prevê-se a constituição de uma coordenação do programa em nível estadual visando a articular os diferentes agentes e, no âmbito dos municípios, há a necessidade de que os projetos sejam aprovados por um conselho (Conselho Municipal de Desenvolvimento Rural Sustentável, Conselho de Segurança Alimentar etc.) (MDA, 2012).

A origem dos recursos utilizados no programa variou ao longo do tempo. Entre os anos de 2003 e 2005, o PAA foi operacionalizado somente com recursos do MDS através do Fundo de Combate e Erradicação à Pobreza, sendo desenvolvido pela Secretaria Nacional de Segurança Alimentar (SESAN) em parceria com governos municipais e estaduais, e com a CONAB. A partir do ano de 2006, o MDA, por intermédio da Secretaria da Agricultura Familiar, passou a compor o Conselho Gestor do programa com dotação orçamentária própria, disponibilizando recursos para a aquisição de produtos e a formação de estoques dos agricultores e de suas organizações (VIANA; VIEGAS, 2009).

No período 2003-2010, o MDS foi responsável por mais de $89 \%$ dos recursos utilizados no programa. Essa predominância dos recursos oriundos do MDS se deve ao maior número de modalidades do programa executadas por esse ministério, como se pode observar no quadro 1 . Nesse quadro se apresentam também as cinco modalidades do programa e suas características, fonte de recursos, executores e formas de acesso.

Destaca-se que é possível aos produtores, ou suas organizações, acessarem mais de uma modalidade do PAA simultaneamente, desde que sejam atendidos os critérios estabelecidos no programa.

A CONAB tem a função de credenciar as entidades beneficiadas com o PAA e os polos de compras, sejam cooperativas ou associações de produtores rurais. Cabe também à CONAB repassar aos polos de compra o padrão de qualidade dos alimentos entregues pelos agricultores e que é estabelecido pelo MAPA. 
Programa de Aquisição de Alimentos: Limites e potencialidades de políticas de segurança alimentar para a agricultura familiar Rosangela Aparecida de Medeiros Hespanhol

Quadro 1: Modalidades do PAA, Características, Fonte de Recursos, Executores e Forma de Acesso.

\begin{tabular}{|c|c|c|c|c|}
\hline Modalidades & Características & $\begin{array}{l}\text { Fonte de } \\
\text { Recursos }\end{array}$ & Executor & $\begin{array}{l}\text { Forma de } \\
\text { acesso }\end{array}$ \\
\hline $\begin{array}{l}\text { 1.Compra para } \\
\text { Doação Simul- } \\
\text { tânea } \\
\text { (CPR Doação) }\end{array}$ & $\begin{array}{l}\text { Destina-se a promover a articulação entre a produção de } \\
\text { agricultores organizados e as demandas locais de entida- } \\
\text { des que compõem a Rede de Proteção e Promoção Social } \\
\text { que tenham programas e ações de acesso. }\end{array}$ & MDS & $\begin{array}{l}\text { CONAB, } \\
\text { Estados e } \\
\text { Municípios }\end{array}$ & $\begin{array}{l}\text { Individu- } \\
\text { al, grupos } \\
\text { informais, } \\
\text { cooperativas e } \\
\text { associações }\end{array}$ \\
\hline $\begin{array}{c}\text { 2.Formação de } \\
\text { Estoques }\end{array}$ & $\begin{array}{l}\text { Visa à comercialização dos produtos, sustentação de pre- } \\
\text { ços e agregação de valor. Ao identificar a possibilidade } \\
\text { de formação de estoque de determinado produto, a orga- } \\
\text { nização de agricultores envia uma Proposta de Participa- } \\
\text { ção à Conab da região. A proposta deve conter o produto } \\
\text { definido, o prazo para a formação do estoque, os preços e } \\
\text { os agricultores a serem beneficiados. Com a aprovação, a } \\
\text { organização emite a Cédula de Produto Rural (CPR-Es- } \\
\text { toque), e a Conab disponibiliza o recurso. A organização } \\
\text { adquire a produção dos agricultores listados na Proposta } \\
\text { de Participação, beneficia os alimentos e os mantém em } \\
\text { estoque próprio até sua entrega ou comercialização. }\end{array}$ & $\begin{array}{l}\text { MDS e } \\
\text { MDA }\end{array}$ & CONAB & $\begin{array}{c}\text { Cooperativas e } \\
\text { associações de } \\
\text { produtores }\end{array}$ \\
\hline $\begin{array}{l}\text { 3.Compra Dire- } \\
\text { ta da Agricultu- } \\
\text { ra Familiar } \\
\text { (CDAF) }\end{array}$ & $\begin{array}{l}\text { Aquisição de alimentos para distribuição ou para forma- } \\
\text { ção de estoques públicos. Cumpre um importante papel } \\
\text { na promoção da segurança alimentar e nutricional, na re- } \\
\text { gulação de preços de alimentos e na movimentação de sa- } \\
\text { fras e estoques. Permite a aquisição de produtos, a preços } \\
\text { de referência, definidos pelo Grupo Gestor do Programa. } \\
\text { Depois pode ser entregue nas Unidades Armazenadoras } \\
\text { da Conab ou em Polos Fixos e Volantes de Compra. }\end{array}$ & $\begin{array}{l}\text { MDS e } \\
\text { MDA }\end{array}$ & CONAB & $\begin{array}{l}\text { Individu- } \\
\text { al, grupos } \\
\text { informais, } \\
\text { cooperativas e } \\
\text { associações }\end{array}$ \\
\hline $\begin{array}{l}\text { 4. Incentivo } \\
\text { à Produção e } \\
\text { Consumo do } \\
\text { Leite } \\
\text { (PAA Leite) }\end{array}$ & $\begin{array}{l}\text { Destina-se a incentivar o consumo e a produção familiar } \\
\text { de leite, visando diminuir a vulnerabilidade social, com- } \\
\text { batendo a fome e a desnutrição nos estados do Nordeste } \\
\text { e no norte de Minas Gerais, mediante a aquisição do } \\
\text { produto com garantia de preço. Para participar o produtor } \\
\text { deve produzir no máximo 100L de leite/dia; possuir De- } \\
\text { claração de Aptidão ao Pronaf (DAP); e ter comprovante } \\
\text { de vacinação dos animais. }\end{array}$ & MDS & $\begin{array}{c}\text { Estados do } \\
\text { NE e MG } \\
\text { (norte) }\end{array}$ & $\begin{array}{l}\text { Individu- } \\
\text { al, grupos } \\
\text { informais, } \\
\text { cooperativas e } \\
\text { associações }\end{array}$ \\
\hline $\begin{array}{l}\text { 5. Compra } \\
\text { Institucional }\end{array}$ & $\begin{array}{l}\text { Destina-se a atender as demandas alimentícias regulares } \\
\text { de instituições, como restaurantes universitários, unida- } \\
\text { des prisionais, hospitais, academias de polícia etc. Órgãos } \\
\text { municipais, estaduais e federais poderão comprar, por } \\
\text { meio desta modalidade produtos da agricultura familiar. }\end{array}$ & Proponente & Proponente & $\begin{array}{c}\text { Cooperativas e } \\
\text { associações }\end{array}$ \\
\hline
\end{tabular}

Fonte: Ministério do Desenvolvimento Agrário (2012).

Soc. \& Nat., Uberlândia, 25 (3): 469-483, set/dez/2013 
Em termos de valores pagos aos agricultores participantes do PAA, desde setembro de 2009, os valores são de $\mathrm{R} \$ 4.500,00$ por ano/produtor na modalidade CPR Doação; de R \$ 4.500,00 por semestre/produtor no PAA Leite; e de R \$ 8.000,00 no PAA Formação de Estoque e CDAF.
Na modalidade PAA Compra Institucional, criada recentemente (julho de 2012), o valor máximo é de R $\$ 8.000,00$ por ano/produtor.

Em termos de evolução do PAA na escala nacional, na tabela 1 são apresentadas informações do período 2003-2011.

Tabela 1 - PAA: Número de produtores, volume de recursos e pessoas beneficiadas - 2003 - 2011.

\begin{tabular}{cccc}
\hline Ano & $\begin{array}{c}\text { Agricultores } \\
\text { participantes }\end{array}$ & $\begin{array}{c}\text { Valores } \\
\text { (Milhões de } \\
\text { R\$) }\end{array}$ & $\begin{array}{c}\text { Pessoas } \\
\text { atendidas }\end{array}$ \\
\hline $2003^{*}$ & 41.988 & 164,7 & 39.500 \\
2004 & 68.700 & 179,3 & 3.339 .189 \\
2005 & 87.439 & 333,1 & 4.356 .191 \\
2006 & 111.030 & 374,3 & 8.681 .933 \\
2007 & 92.372 & 228,3 & 7.580 .948 \\
2008 & 91.622 & 275,9 & 10.643 .207 \\
2009 & 137.185 & 363,4 & 13.345 .908 \\
2010 & 155.166 & 379,7 & 16.622 .430 \\
2011 & 161.121 & 665,3 & 20.178 .450 \\
\hline
\end{tabular}

Fonte: Dados referentes aos anos de 2003 a 2006 estão disponíveis em VEIGA (2008); de 2007 e 2008 em VIANA; VEGAS (2009); de 2009 e 2010 em MDS (2012); e 2011 no PAA DATA/SAGI (2012).

A despeito da ampliação ocorrida no período 2003-2011 em relação ao número de produtores envolvidos, volume de recursos utilizados e pessoas beneficiadas, a abrangência do programa ainda é bastante limitada em nível nacional. Se considerarmos apenas o número de produtores participantes do PAA em 2011, verificamos que representam apenas 3,68\% do total de estabelecimentos de agricultores familiares contabilizados pelo Censo Agropecuário do IBGE de 2006. Constata-se, assim, que é um número bastante modesto pela importância que esta política possui em relação à agricultura familiar e à segurança alimentar no país.
Além da expansão limitada do programa em escala nacional, verifica-se que há concentração, por exemplo, em termos do número de produtores beneficiados. Assim, constatamos que no ano de 2006, dos produtores participantes do PAA, 67,2\% estavam concentrados em apenas duas macrorregiões do país: Nordeste $(35,3 \%$ do total) e Sul (31,9\%), com participação reduzida das demais, como se pode verificar na Figura 1.

Ainda em relação a essas duas macrorregiões, as unidades da federação que mais se destacaram no ano de 2006 em termos de produtores beneficiados com o programa foram o Rio Grande do Norte (representando $73,1 \%$ do total regional do NE) e o Paraná (representando $42,9 \%$ do total regional do Sul). 
Figura 1 - Número de Produtores Rurais no PAA - 2006 e 2011.

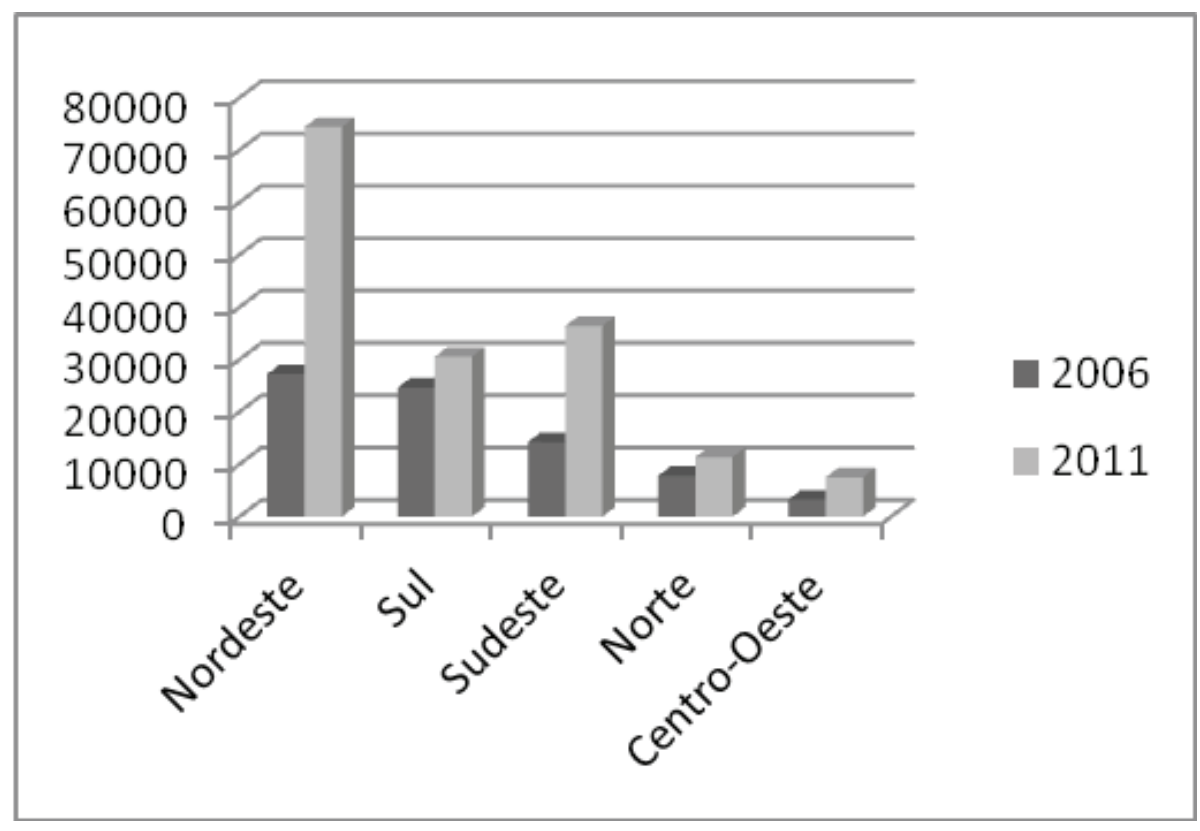

Fonte: PAA DATA (2006 e 2011).

No ano de 2011, como se pode observar na Figura 1, houve a ampliação do número de agricultores participantes do PAA em todas as macrorregiões brasileiras. Todavia, a concentração espacial dos produtores participantes do programa permanece em duas macrorregiões, que detém $69,1 \%$ do total, com destaque para o Nordeste (46,4\%) e o Sudeste (22,7\%); enquanto o Sul (19,1\%) aparece em terceiro lugar, seguido pelas demais. Em âmbito estadual, destacam-se Pernambuco (com 19,1\% dos produtores do NE), São Paulo (com $39,4 \%$ dos produtores do SE) e Paraná (com 48,9\% dos produtores do $\mathrm{Sul}$ ).

O mesmo nível de concentração verificada em nível das macrorregiões se reproduz em termos de unidades da federação. Essa concentração pode ser justificada pelo maior grau de organização coletiva dos produtores beneficiados e da maior divulgação do programa nestas unidades da federação. Todavia, de forma geral, o que se pode afirmar é que o número de produtores beneficiados pelo PAA ainda é muito reduzido se comparado ao universo de agricultores de pequeno porte que encontram dificuldades para comercializar a produção (HESPANHOL, 2009).

No que se refere aos recursos utilizados no PAA, por modalidade, constata-se que, do total aplicado no período 2003-2010, a Compra com Doação
Simultânea (CPR Doação) se destacou (39\%), aparecendo na sequência o PAA Leite (37\%), que atende exclusivamente a Região Nordeste do país e o norte de Minas Gerais (CONSAD, 2010). As modalidades Compra Direta e Formação de Estoques tiveram menor volume de recursos alocados no período (13\% e $8 \%$, respectivamente) e a Compra Antecipada somente operou no anos de 2003 e 2004 (CONSAD, 2010).

De acordo com Viana; Viegas (2009), a modalidade CPR-Doação é a que mais tem obtido recursos do programa em virtude do seu acesso mais simplificado. Esses autores enfatizam que:

O número de projetos aumentou ao longo dos anos, principalmente na modalidade CPR-Doação. Isto se deu por esta modalidade permitir aquisição ao longo de todo o ano e contemplar maior diversidade de produtos (frutas, legumes, verduras, carnes, doces, peixes, produtos regionais e de extrativismo etc.), ou seja, a participação do agricultor pode ocorrer com a movimentação dos produtos que ele já dispõe e que tradicionalmente cultiva em sua propriedade, valorizando os produtos locais. (VIANA;VIEGAS, 2009, p. 150). 
Considerando a importância social desse programa e as limitações apresentadas em escala nacional, nos detivemos na análise do PAA - Doação Simultânea no Município de Dracena (SP). A escolha de uma área específica para a realização da pesquisa empírica se deve ao fato de que como destaca Santos (1996, p. 256), a escala local é importante, pois "é o lugar que oferece ao movimento do mundo a possibilidade de sua realização mais eficaz. Cada lugar se define tanto por sua existência corpórea, quanto por sua existência relacional." Dessa forma, o lugar deve ser apreendido como "um cotidiano compartido entre as mais diversas pessoas, firmas e instituições - [onde] cooperação e conflito são a base da vida em comum." (SANTOS, 1996, p. 258)
Na perspectiva desse autor, a Geografia assume importância fundamental no período atual ao analisar o que cada lugar tem de singular, de específico, de diferente, sem perder, no entanto, a visão de totalidade.

\section{MUNICÍPIO DE DRACENA NO CONTEXTO REGIONAL}

O município de Dracena faz parte da Microrregião Geográfica de Dracena (MRG), situada na porção Oeste do Estado de São Paulo (Figura 2).

Esse município possui área de $500 \mathrm{Km}^{2} \mathrm{e}$ constitui-se na sede dessa microrregião, exercendo maior centralidade na rede urbana regional em virtude de concentrar uma maior variedade de equipamentos, infraestrutura e serviços urbanos.

Figura 1: Localização do município de Dracena na MRG de Dracena.

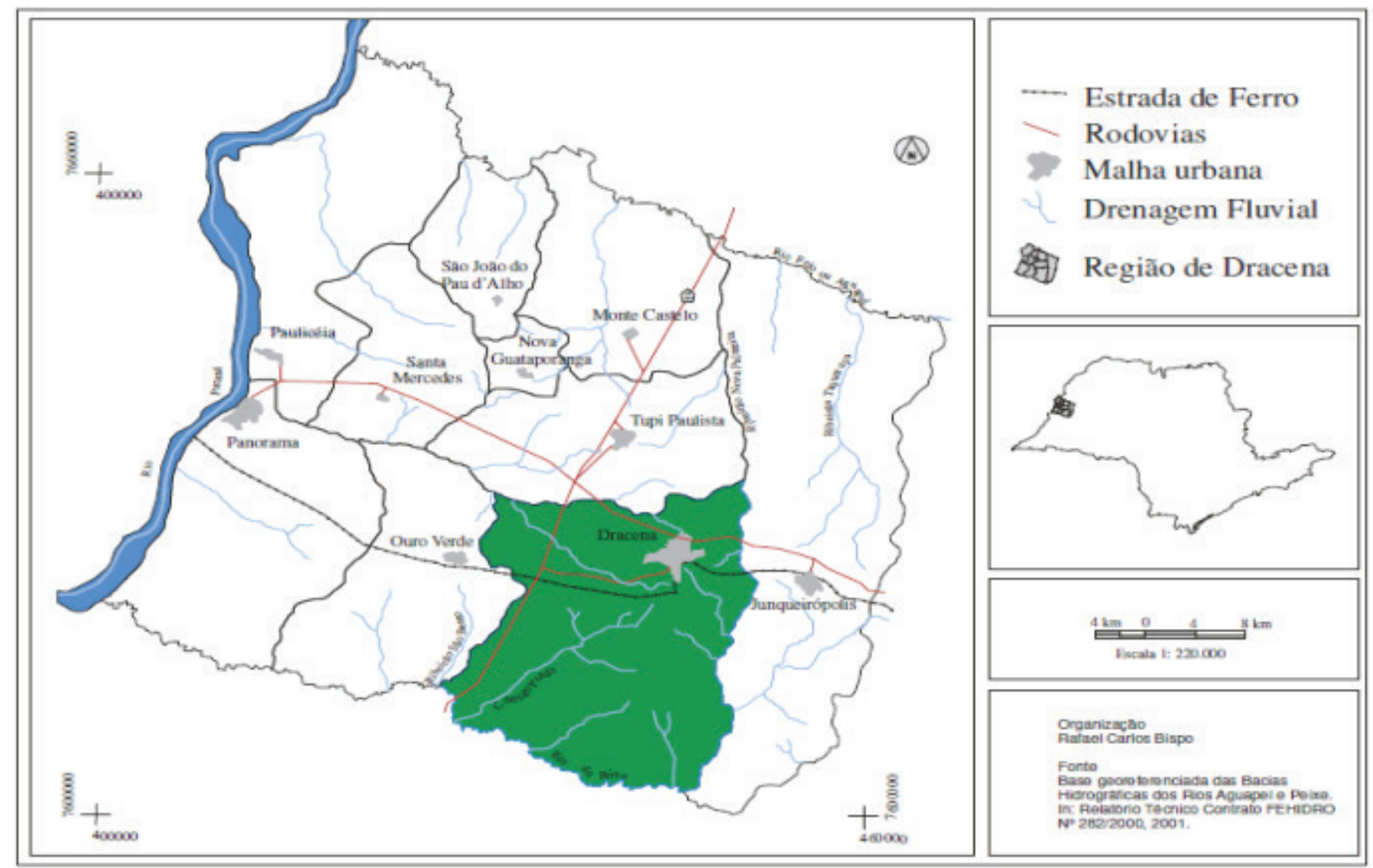

Org. da autora.

Essa região, que ocupa uma extensão territorial de $2.862 \mathrm{~km} 2$, é formada por dez (10) municípios de pequeno porte que, por exercem poucas funções urbanas em termos de infraestrutura e equipamentos, são polarizados por
Dracena. Em termos populacionais, essa região abarcava no ano de 2010 um contingente demográfico de 116.149 habitantes, sendo que $88,2 \%$ residiam nos núcleos urbanos e $11,8 \%$ nas áreas rurais (IBGE, 2010). 
A economia dessa microrregião apresenta baixa expressividade do seu setor industrial, assumindo significativa relevância em termos de absorção de pessoal e de arrecadação de impostos, as atividades ligadas ao comércio e à prestação de serviços. Na maior parte dos municípios que compõem essa microrregião, o setor agropecuário ainda desempenha grande importância. Isso porque, as demandas geradas a partir dessa atividade e dos moradores do espaço rural, sejam elas diretas (compra de insumos e equipamentos; consertos de máquinas e implementos; comercialização da produção; acesso ao crédito rural etc.) e/ou indiretas (aquisição de gêneros alimentícios, de limpeza e higiene pessoal; eletrodomésticos; medicamentos etc.), têm seus efeitos no comércio e no setor de prestação de serviços situados nas pequenas cidades da região.

Wanderley (2001) destaca que em pequenas cidades do interior do Brasil, principalmente nas mais afastadas dos grandes centros metropolitanos, o rural ainda é fortemente estruturado no setor agropecuário.

Nessas localidades, as particularidades entre o rural e o urbano são fontes de integração e de cooperação.

Não obstante a importância da agricultura para a região, esta passou, no período recente, por um processo de reestruturação produtiva, expressa na crise da cafeicultura nos anos 1980 e a expansão do setor sucroalcooleiro nos anos 1990 e 2000, resultando na intensificação da migração campo-cidade e da concentração fundiária.

Em virtude da grande presença de pequenos estabelecimentos agropecuários, que se dedicavam a cafeicultura e a policultura, com a crise econômica, tiveram que procurar novas alternativas produtivas, destacando-se: a fruticultura, destinada tanto ao processamento industrial (maracujá, manga, goiaba etc.) como ao consumo in natura (uva e coco-anão); o cultivo de seringueira para a extração de látex e do urucum, bem como a pecuária mista (HESPANHOL, 2007).

Essas atividades, embora tenham garantido a manutenção da família - ou de parte desta, já que muitos filhos destes produtores migraram para as cidades à procura de melhores condições de vida - e da propriedade da terra, têm apresentado limitações, já que em virtude da escala de produção ser pequena, há a subordinação dos produtores aos interesses dos intermediários (cerealistas) e do setor agroindustrial que atua na região.
Para minimizar o problema da pequena escala de produção, uma alternativa encontrada pelos produtores rurais e, inicialmente estimulada pelos técnicos extensionistas das Casas da Agricultura e, mais recentemente, a partir de meados dos anos 1990, pelas políticas públicas, tem sido a organização coletiva por meio do associativismo rural.

Silveira et. al. (1999) observam que a organização coletiva expressa por meio das associações de produtores deve ser entendida como resposta a uma situação em que a ação individual não consegue atender as demandas e as reivindicações de determinados segmentos sociais.

Nesse contexto, as associações de produtores rurais surgem em razão da incapacidade de outros canais de representação, como os sindicatos rurais e as cooperativas, de darem respostas satisfatórias e constantes às demandas dos agricultores, constituindo-se num importante meio para a viabilização de pequenos produtores rurais frente aos altos custos de produção, das exigências tecnológicas, das dificuldades de comercialização ou mesmo para participarem dos programas governamentais, como o PAA e o Programa Nacional de Alimentação Escolar (PNAE).

$\mathrm{O}$ próprio governo federal tem induzido à organização coletiva no espaço rural ao condicionar a participação dos produtores rurais em programas, como algumas modalidades do PAA, desde que organizados em associações ou cooperativas. Verifica-se, assim, como essas políticas têm incentivado ou fortalecido a organização coletiva dos produtores rurais, embora muitas dessas experiências estejam estreitamente vinculadas à possibilidade de recebimento de recursos públicos e/ou à participação nos programas de âmbito estadual ou federal.

O município selecionado para a realização da pesquisa, ou seja, Dracena, se constitui, de certa forma, em exemplo interessante, já que as duas associações de produtores rurais existentes nessa localidade - Associação dos Produtores Rurais de Dracena (APDR) e Associação J. Marques dos Trabalhadores Rurais do Distrito de Jaciporã -, apesar das inúmeras dificuldades enfrentadas, encontram-se relativamente bem estruturadas, seja em termos materiais (de sede, de funcionários e de equipamentos de informática), de participação dos produtores associados, como de articulações políticas, seja na esfera municipal (prefeitura, Casa da Agricultura, 
cooperativas e sindicatos, agroindústrias, SEBRAE etc.), regional (Escritório de Desenvolvimento Rural, universidades públicas etc.) e até mesmo estadual.

\section{PAA DOAÇÃO SIMULTÂNEA NO MUNICÍPIO DE DRACENA}

Os primeiros projetos do PAA estabelecidos na MRG de Dracena ocorreram no ano de 2006, nos municípios de Dracena, Tupi Paulista e Junqueiró- polis (HESPANHOL, 2008 e 2009). Desde então e, sobretudo a partir do ano de 2008, o programa tem se expandido para outros municípios da região.

Em relação ao município de Dracena, os dados fornecidos pelo Escritório de Desenvolvimento Rural (EDR) evidenciam que no período compreendido entre os anos de 2006 e 2011, o PAA apresentou significativo crescimento em termos do número de produtores participantes, entidades beneficiadas e do valor total das operações, como se pode verificar na tabela 2 .

Tabela 2. PAA: Número de produtores, entidades e valor total no Município de Dracena - SP 2006-2011.

\begin{tabular}{ccccccc}
\hline & $\mathbf{2 0 0 6}$ & $\mathbf{2 0 0 7}$ & $\mathbf{2 0 0 8}$ & $\mathbf{2 0 0 9}$ & $\mathbf{2 0 1 0}$ & $\mathbf{2 0 1 1}$ \\
\hline Produtores & 62 & 134 & 184 & 206 & 90 & 230 \\
Entidades & 26 & 40 & 46 & 34 & 16 & 26 \\
Valor total (em reais) & 207.500 & 423.500 & 644.000 & 914.500 & 387.428 & 975.131 \\
\hline
\end{tabular}

Fonte: Escritório de Desenvolvimento Rural de Dracena (2011). Org. da autora.

Entre os anos de 2009 e 2010 ocorreu redução tanto em relação ao número de produtores, entidades e o valor total das operações. De acordo com o responsável pelo EDR de Dracena, isso ocorreu em virtude do atraso na elaboração do plano anual do PAA, na modalidade Doação Simultânea, resultando na redução no numero de produtores participantes, instituições e valor dos recursos. No ano de 2011, além do plano anual do PAA - Doação Simultânea ter sido elaborado no período correto, foram aprovados projetos na concessão da modalidade Formação de Estoques, resultando no crescimento do número de produtores rurais participantes e valores recebidos do programa.

Nessas duas modalidades, participavam tanto os associados da APRD, constituído, sobretudo de pequenos proprietários rurais, como da Associação J. Marques dos Trabalhadores Rurais do Distrito de Jaciporã, em que há grande presença de pequenos arrendatários de terra e trabalhadores rurais, segundo informações do responsável pelo EDR de Dracena.

Considerando o fato de que a APRD foi uma das primeiras associações a participar do PAA Doação Simultânea na região, optamos por focar nossa análise nos produtores rurais que fazem parte dessa organização coletiva.

\section{Gestão do PAA Doação Simultânea pela Associação dos Produtores Rurais de Dracena (APRD)}

AAssociação de Produtores Rurais de Dracena - APRD - conta com aproximadamente 200 associados. Segundo a presidente da associação, os principais serviços oferecidos são: aluguel de maquinários agrícolas (tratores e implementos); compra coletiva de insumos (defensivos, calcário, fertilizantes etc.), com melhores condições de pagamento e de prazo, além da disponibilização de mudas de várias espécies de plantas produzidas no viveiro do município.

Apesar do grande número de associados, a entrevistada relatou que participam efetivamente da associação apenas 90 produtores. Uma das mais importantes atividades desenvolvidas pela associação é a organização do Programa de Aquisição de Alimentos (PAA), na modalidade Doação Simultânea e Formação de Estoque, em que participam cerca de 60 produtores. A associação também promove a comercialização coletiva de leite para a Cooperativa Agrícola Mista de Adamantina (CAMDA), da qual participam 48 produtores associados. 
No caso da APRD, o PAA Doação Simultânea é realizado por meio de convênio estabelecido com a CONAB. A operacionalização dessa modalidade do programa nesta associação envolve desde a fase de elaboração do projeto (proposta) até a entrega dos produtos às entidades assistenciais de Dracena (14), Ouro Verde (01) e Panorama (01), já que a associação centraliza na sua sede todas as atividades.

Assim, os agricultores entregam, por meio de transporte próprio, seus produtos na associação semanalmente (às terças-feiras das 07:30 às 10:30 horas). Essa, por meio de seus funcionários, fica incumbida de vistoriar e certificar a qualidades dos alimentos, organizando a distribuição dos produtos às entidades sociais cadastradas no programa. Caso o produto não apresente condições em termos de qualidade, a entrega à entidade pode não ser efetuada e, consequentemente, o produtor não receberá o pagamento. De acordo com a presidente da associação, o número de casos em que os produtos não são aceitos pelas entidades assistenciais devido à qualidade inferior é muito pequeno, pois o produtor sabe que corre o risco de não ser cadastrado no momento de renovação do projeto junto à CONAB.

\section{Perfil dos produtores rurais participantes do PAA Doação Simultânea e avaliação}

No ano de 2010, na APRD, 60 produtores estavam cadastrados no PAA, sendo que os principais produtos comercializados eram: café, batata-doce, mandioca, abóbora, frutas (principalmente acerola, banana, uva, mamão e coco verde), leite (processado), polpas de frutas para suco e pão caseiro, que é produzido na cozinha industrial da associação por algumas mulheres de produtores rurais que participam do programa. Nesse local também são ministrados cursos de derivados de leite (queijo, doce etc.), de compotas, entre outros.

Em relação aos produtores se verificou, por meio das entrevistas, que todos eram proprietários rurais, sendo que a extensão territorial das propriedades variava de 05 a 15 hectares e estavam localizadas, em sua maioria (75\%), no entorno da cidade, num raio de até $10 \mathrm{~km}$ da sede da associação.

A maioria (85\%) dos produtores é casada e reside na propriedade há mais de 20 anos. O número de filhos por casal varia de dois a quatro, sendo que na maioria dos casos $(75 \%)$ os filhos, casados e / ou solteiros, não mais residem na propriedade rural, mas na cidade de Dracena ou em outras localidades, como São Paulo, Americana, Limeira, Campinas etc., exercendo ocupações urbanas.

A idade média dos produtores era de 50 anos e, na maioria dos casos (55\%), eles informaram ter concluído o ensino fundamental.

Os rendimentos monetários brutos mensais dos produtores podem alcançar, segundo as informações prestadas, mais de quatro salários mínimos - no período de realização da pesquisa de campo (Fevereiro de 2010), o valor do salário mínimo mensal no país era de $\mathrm{R} \$ 510,00$-, sendo que a média era de dois.

Podemos constatar que as atividades agropecuárias (pecuária de leite e corte; fruticultura; café e lavouras diversificadas) constituem-se nas principais fontes de renda de $63,2 \%$ dos produtores entrevistados, enquanto que para $26,3 \%$ a aposentadoria se destaca em termos monetários e para $10,5 \%$ a ocupação em atividades não agrícolas, realizadas dentro ou fora da propriedade rural, era mais importante. A partir dessas informações, podemos concluir que a agricultura se constitui na principal fonte de renda monetária dos produtores, sendo que a possibilidade de comercializar parte da produção junto ao PAA se constitui em importante alternativa para se aumentar a renda monetária mensal das famílias.

O PAA ao garantir a comercialização de parte da produção e, aproximar os produtores dos consumidores - no caso as entidades assistenciais -, estimula a diversificação produtiva, por meio das compras governamentais de alimentos. Esse fato foi constatado ao se verificar que a maioria $(60 \%)$ dos produtores informou que desde o início do programa no município em 2006, já ampliou a área cultivada e diversificou a sua produção, com o cultivo de novos produtos destinados ao PAA; enquanto que os demais $40 \%$ não expandiram e declararam nas entrevistas que não tem essa intenção, seja porque a área de cultivo na propriedade é muito pequena (15\%); por não terem condições econômicas (15\%) ou por terem receio da descontinuidade do programa $(10 \%)$ em virtude da sua não renovação. 
Com relação à contribuição do programa a diversificação produtiva, Ghizelini (2006, p.1) destaca que:

O PAA enquanto ação pública permitiu alguns avanços na forma como o Governo analisa, compreende e atua diante do quadro de pobreza e insustentabilidade atual da agricultura familiar brasileira [...] que se vê atrelada a produzir produtos que o mercado aceita comercializar [...], consequentemente, a produzir produtos agricolas [...] que permitem às agroindústrias ter uma margem de lucro cada vez maior. Aqueles alimentos e produtos que não possibilitam reproduzir esta lógica, não possuem mercado, ou como dizem, estão "fora" do mercado.

Este modelo de agricultura não inviabilizou apenas a diversificação de produtos para a comercialização, mas fundamentalmente, reduziu a capacidade dos agricultores familiares de produzirem alimentos em quantidade e diversidade para sua sustentabilidade alimentar. Esta estratégia promoveu a destruição quase que completa das redes de produção e abastecimento local de alimentos, o que foi rapidamente substituido pelos alimentos industrializados ou mesmo importados de outras regiões.

Constatou-se nas entrevistas a satisfação dos produtores com o programa. Do total, $95 \%$ dos entrevistados o avaliaram como muito bom, já que o PAA tem representado a garantia de comercialização de parcela da produção.

Para parte dos produtores (45\%), o ideal é que o valor pago (cota anual) do PAA fosse aumentado para que eles pudessem entregar toda a sua produção no programa, não necessitando mais de outros canais de comercialização, além de que fosse pago as despesas com o transporte até o local da entrega. Para outra parcela dos produtores $(30 \%)$, o valor pago poderia ser aumentado, mas mesmo assim gostariam de continuar comercializando a produção em outros locais que já atuam, como nas feiras, nos supermercados etc., pois temem dependerem apenas de uma forma de comercialização, pois como comentou um produtor "se o governo ou a política muda (sic), a gente não sabe como o programa vai ficar" (M.S.G, 48 anos, Fev. 2010). Os demais (25\%) afirmaram estar satisfeitos com o programa, embora também avaliassem que os preços pagos pelo PAA deveriam ser reajustados.

Com relação ao preço pago aos produtos entregues no PAA pela CONAB, verificou-se que, por basear-se no mercado regional (no caso paulista, nos preços praticados na Companhia de Entrepostos e Armazéns Gerais do Estado de São Paulo - CEAGESP), este é mais vantajoso ao produtor por não haver o intermediário no momento da comercialização. Em virtude da pequena escala de produção, a comercialização sempre se constituiu num verdadeiro entrave aos pequenos produtores rurais. Não se quer com isso afirmar que o PAA esteja resolvendo o problema da intermediação ou da dependência dos produtores ao mercado, já que se constatou na pesquisa de campo que a maioria $(80 \%)$ dos cadastrados no programa na APRD, se utiliza de outros canais de comercialização para se manterem economicamente na atividade.

Todavia, sobretudo para os pequenos proprietários rurais menos capitalizados e com maiores dificuldades de inserção no mercado, o PAA tem se constituído numa alternativa em termos de complementação de renda, assegurando um valor de $\mathrm{R} \$ 4.500,00$ por produtor ao ano. Apesar de relativamente baixa (algo em torno de $\mathrm{R} \$ 375,00$ por mês), essa renda, quando combinada com outras (comercialização da produção em outros canais, recebimento da aposentadoria rural, emprego não agrícola de membros da família etc.), tem sido importante na composição do orçamento familiar. Assim, constatou-se que uma das principais reivindicações dos produtores pesquisados foi a necessidade de se rever o valor da cota anual estabelecida pelo programa, bem como o ressarcimento com o transporte dos produtos.

A incerteza com relação à continuidade do programa ou mesmo a renovação do PAA foi um dos aspectos mais lembrados pelos produtores $(90 \%)$ e que gera uma situação de insegurança em termos de novos investimentos nas atividades agropecuárias. Nessa perspectiva, alguns autores têm destacado a necessidade do PAA se tornar uma política de Estado e não apenas de Governo, já que uma política de governo resume-se a um ou dois mandatos, enquanto 
uma política de Estado tende a ser permanente. Nesse sentido, Deves (2009) aponta a Lei no 11.947 de 16 de Junho de 2009 como um importante avanço, ao definir que do total dos recursos financeiros repassados pelo FNDE (Fundo Nacional de Desenvolvimento da Educação) aos Estados, Distrito Federal e Municípios, no mínimo $30 \%$ deverão ser utilizados na aquisição de gêneros alimentícios diretamente da agricultura familiar ou de suas organizações. Amplia-se, assim, a possibilidade de inserção dessa categoria de produtores nos mercados institucionais, ou seja, nas compras governamentais de alimentos.

Outro problema aventado por alguns (25\%) produtores foi a falta de beneficiamento de determinados produtos, como no caso da batata doce e da abóbora, já que a APRD consegue pasteurizar o leite entregue no PAA, pois dispõe de um convênio via prefeitura municipal com Cooperativa Agrícola Mista de Adamantina (CAMDA) e beneficia as frutas, transformando-as em polpas, em virtude de acordo com a Empresa Fruteza, que atua no município no processamento de frutas. Foram destacadas também pelos produtores rurais algumas dificuldades institucionais, como a necessidade de ações mais articuladas, principalmente em relação à assistência técnica e ao crédito rural visando resolver problemas vinculados ao processo produtivo.

Não obstante essas dificuldades, um aspecto ressaltado tanto pela presidente da APRD como por vários produtores rurais entrevistados, refere-se ao fato de com o PAA eles se sentiram valorizados, já que a produção destina-se às entidades assistenciais que atuam no município de Dracena ou em outros próximos, beneficiando pessoas carentes e/ou doentes, dando maior visibilidade e reconhecimento ao trabalho realizado por esses sujeitos sociais. Uma consequência importante dessa aproximação entre a demanda das entidades assistenciais e os produtores de gêneros alimentícios diz respeito à intensificação das relações e das articulações entre campo e cidade, na perspectiva do fortalecimento de redes locais e/ou regionais de comercialização da produção.

Foi destacado também por alguns produtores a importância desempenhada pela APRD no âmbito do PAA como instância articuladora das instituições públicas na escala local, como a prefeitura municipal, a Casa de Agricultura, o Conselho Municipal de Desenvolvimento Rurais (CMDR), as entidades assistenciais etc. e mesmo em escala regional, com o EDR de Dracena, a CAMDA e entidades assistenciais que atuam em outros municípios e que recebem os produtos pelo programa.

Verifica-se, assim, que o PAA fomenta "uma nova e complexa rede de diversos atores dedicados à operacionalização do PAA, locados desde o nível nacional até o local" (GRISA, 2009, p. 14). Todavia, na avaliação de Grisa (209), a rede fomentada pelo PAA é fechada, na medida em que somente os produtores rurais que possuem a DAP e, na nossa avaliação estão organizados coletivamente, por meio de grupos informais (com no mínimo cinco agricultores), associações e cooperativas, podem participar do programa.

Não obstante essa limitação, a referida autora destaca que o PAA:

[...] envolve uma rede de atores dedicados à elaboração da proposta do PAA. Estes atores foram agrupados pela proximidade com o tema, mas também por laços sociais anteriormente estabelecidos. Na sua estrutura organizacional, já na execução do programa, o PAA se apresenta na forma de uma imensa rede de atores estatais e da sociedade civil localizados desde o nivel nacional até a escala local. Nos contextos locais, o PAA se expressa na forma de "um emaranhado de nós" interligando unidades familiares de produção e estas com suas associações/cooperativas, instituições públicas, instituições sociais, famílias beneficiarias e, ainda, todos estes com a estrutura ao nivel nacional. (GRISA, 2009, p. 19).

Verifica-se, assim, apesar das limitações e dificuldades do programa, as contribuições que o PAA propicia ao fomentar (ou fortalecer) o estabelecimento de redes sociais, não apenas em escala nacional entre os gestores, os conselhos e as organizações da sociedade, mas sobretudo na escalas local e regional, em que as ações são efetivamente operacionalizadas e as influências político-partidárias, coronelistas e paternalistas estão mais presentes. 


\section{O PAA Doação Simultânea na avaliação das entida- des da rede socioassistencial}

As pesquisas realizadas sobre o PAA têm demonstrado que o programa ganhou importância nas localidades estudadas, não só por beneficiar os produtores rurais participantes, mas também as entidades socioassistenciais que integram a rede local.

No ano de 2010, no PAA Doação Simultânea, 16 entidades participaram do programa no município de Dracena.

Os produtos entregues às entidades beneficiam um público bastante amplo e diversificado, constituído por crianças, idosos, moradores de rua, portadores de deficiência e enfermidades, entre outros. O programa atende também a Santa Casa de Misericórdia do município e a prefeitura, que utiliza os produtos tanto na merenda escolar quanto na distribuição de cestas básicas à população carente. Além das entidades do município de Dracena, o programa também beneficia instituições que atuam em Ouro Verde e Panorama (localizados na MRG de Dracena), o que evidencia a capilaridade do programa.

De forma geral, os responsáveis pelas entidades estão muito satisfeitos com o PAA e, durante as entrevistas, vários destacaram que os benefícios do programa vão desde a economia em relação aos gastos com os alimentos, até a melhoria da saúde do público atendido, uma vez que o consumo de alimentos naturais, com qualidade - principalmente quando se trata de crianças e idosos - garante uma maior resistência as doenças.

Parte dos entrevistados (30\%) argumentou que o programa poderia ser ampliado no município de Dracena, incorporando e beneficiando tanto novos produtores rurais que poderiam ser cadastrados no PAA, como as entidades e as pessoas atendidas, visando diversificar a oferta de produtos.

\section{CONSIDERAÇÕES FINAIS}

Buscou-se neste trabalho apresentar algumas reflexões acerca da experiência do Programa de Aquisição de Alimentos (PAA) tanto em nível nacional, como em um contexto local específico, do Município de Dracena.
Se verificou que, em termos nacionais, apesar do aumento do número de produtores, dos recursos disponibilizados e das pessoas que receberam os produtos no período 2003-2011, a abrangência do PAA ainda é limitada e concentrada em termos macrorregionais e estaduais. Além dessas limitações, o programa enfrenta outras dificuldades como a falta de articulação entre as políticas públicas, como o acesso ao crédito rural (PRONAF) e à assistência técnica, que são fundamentais no momento de se decidir pela continuidade ou não das atividades agropecuárias, bem como pelos produtos a serem cultivados.

Essas limitações e dificuldades do programa em escala nacional se refletem, em parte, no Município de Dracena, já que nesta escala as influências político-partidárias são reforçadas. Constatou-se que por ter uma estrutura descentralizada e mais próxima do contexto político local, em que há diferentes e contraditórios interesses, o PAA apresentou também limitações na escala municipal, em virtude do pequeno número de produtores rurais associados inseridos no programa, seja no âmbito da APDR (60 produtores de um total de 200 associados, representando 30\%) ou do município.

Assim, além daqueles fatores que dificultam a expansão do PAA em escala nacional, outros, coexistentes no nível municipal, podem explicar esse baixo nível de participação dos produtores:

a) o programa ainda está em fase de consolidação em nível nacional e as informações oficiais disponíveis são insuficientes devido aos precários canais de divulgação. Nesse sentido, um trabalho de divulgação do programa tem sido realizado pelos responsáveis pelo EDR de Dracena, com o objetivo de ampliar tanto o número de produtores rurais como de municípios envolvidos. Desde então, esse programa tem se difundido para outros municípios da região, beneficiando, sobretudo, os produtores rurais organizados em associações e com capacidade de responder às demandas do programa em termos de quantidade, qualidade e regularidade da oferta de produtos;

b) na esfera dos municípios, não há conhecimento suficiente sobre o funcionamento do programa e de pessoal qualificado nas associações de produtores para elaborar as propostas (planos anuais); 
c) entre os produtores rurais há o receio da falta de continuidade do programa e, como ressaltado por um entrevistado, os agricultores só entraram no programa após terem certeza de que os primeiros cadastrados receberam pelos produtos entregues.

Outro problema destacado se refere ao valor fixo anual pago pelo programa aos produtores cadastrados, sendo uma reivindicação recorrente entre estes a ampliação da cota anual. Em decorrência dessa limitação foi verificado no município pesquisado o favorecimento, em alguns casos, de parentes dos produtores já cadastrados no programa que tentaram aumentar o valor a ser recebido anualmente por meio da inserção de parentes próximos (filhos, sobrinhos, netos etc.), que também possuem a DAP. Com essa prática, o que acaba ocorrendo é uma concentração em termos do número de famílias de produtores rurais beneficiadas com o programa, não havendo necessariamente a priorização daqueles menos capitalizados.

Apesar dessas limitações e dificuldades enfrentadas pelo PAA Doação Simultânea, verificou-se o grande interesse demonstrado pelos produtores rurais do município pesquisado em continuarem participando do programa, com o objetivo de melhorar a renda familiar obtida por meio da produção agropecuária.

Outro aspecto constatado refere-se ao sentimento de valorização expresso pelos produtores rurais na escala local, já que a produção cadastrada destina-se às entidades assistenciais que atuam no município, propiciando maior visibilidade e reconhecimento ao trabalho realizado.

Verificou-se a importância que as compras governamentais, a exemplo do PAA, podem assumir ao incentivarem a diversificação produtiva, $o$ aumento da produção de alimentos para atender ao consumo familiar e as necessidades da rede socioassistencial local/regional, além de promover a valorização dos hábitos alimentares locais, o associativismo rural e a autoestima dos agricultores, propiciando novas alternativas de comercialização da produção, melhorando as condições de reprodução social desses agricultores no campo.

\section{AGRADECIMENTOS}

$\mathrm{O}$ artigo resulta de pesquisa realizada com auxílio financeiro do CNPq - Conselho Nacional de Desenvolvimento Científico e Tecnológico, Brasil.

\section{REFERÊNCIAS}

BRASIL - Ministério do Desenvolvimento Agrário (MDA). Programa de Aquisição de Alimentos (PAA). Disponível em: <http://www.mda.gov.br/portal/saf/ programas/paal> Acessado em 12 de ago. 2012.

GRISA, C. As redes e as instituições do Programa de Aquisição de Alimentos (PAA). Revista Brasileira de Gestão e Desenvolvimento Regional, v. 6, p. 97-129, 2009.

CONSELHO DE SEGURANÇA ALIMENTAR CONSEA. Balanço de Avaliação da Execução do Programa de Aquisição de Alimentos - PAA - 2003 a 2010. Brasília: Grupo Gestor, 2010.

DEVES, O. D. Fortalecimento da agricultura familiar através do Programa de Aquisição de Alimentos-PAA: o caso do município de São Pedro do Butiá-RS. Dissertação (Mestrado em Desenvolvimento Rural). Universidade Federal do Rio Grande do Sul, Porto Alegre, 2009.

GHIZELINI, A. M. Políticas Públicas de Segurança Alimentar como processo de intervenção direta na produção e no consumo de alimentos no Brasil. Disponível em: $<$ http://www.alasru.org/cdalasru2006/11\%20 GT\%20Andr\%C3\%A9\%20Michelato\%20Ghizelini. pdf $>$. Acessado em 07 de março de 2007.

IBGE- Instituto Brasileiro de Geografia e Estatística. Censo Agropecuário. Disponível em: $<$ http://www. sidra.br>. Acessado em 02 de mar. 2012.

IBGE - Instituto Brasileiro de Geografia e Estatística. Censo Demográfico. Disponível em: $<\mathrm{http}$ ://www. sidra.br>. Acessado em 05 de mar. 2012. 
HESPANHOL, R. A. M. Decadência da cafeicultura e pequenas propriedades rurais: alternativas econômicas na MRG de Dracena - SP. In: CONGRESSO BRASILEIRO DE ECONOMIA, ADMINISTRAÇÃO E SOCIOLOGIA RURAL, 45, 2007. Londrina (PR), Anais... SOBER, p. 01-11.

HESPANHOL, R. A. M. Mudança de concepção das políticas públicas para o campo brasileiro: o Programa de Aquisição de Alimentos (PAA). Scripta Nova (Barcelona), v.XII, p.01-08, 2008.

HESPANHOL, R. A. M. O Programa de Aquisição de Alimentos (PAA) na MRG de Dracena (SP). GeoUERJ , v.3, p.64-87, 2009.

HESPANHOL, R. A. M. Segurança alimentar, mercados institucionais e seus efeitos na escala local. In: JORNADAS INTERDISCIPLINARIAS DE ESTUDIOS AGRÁRIOS Y AGROINDUSTRIALES, 7. ANAIS... Buenos Aires: Facultad de Ciências Econômicas (UBA), 2011, p. 1-20.

MALUF, R. S. Políticas agrícolas e de Desenvolvimento rural e de segurança alimentar. In: Leite, S. (Org.). Politicas Públicas e Agricultura no Brasil. Porto Alegre: Editora da UFRGS, p. 58-85, 2001.

MATTEI, L. Programa de Aquisição de Alimentos da Agricultura Familiar (PAA): antecedentes, concepção e composição geral do programa. In: Cadernos do CEAM, UnB, v. 7, 2007, p. 33-44.

PORTO, S. I. Retomada e perspectivas de uma política de comercialização e abastecimento Alimentar. In: Companhia Nacional de Abastecimento. Agricultura e Abastecimento Alimentar: Políticas Públicas e Mercado Agrícola. Brasília: CONAB, 2009, p. 45-54.

SANTOS, M. A. Natureza do Espaço - Técnica e tempo, razão e emoção. São Paulo: Hucitec, 1996.
SILVEIRA, P. R. C. et al. A diversidade do associativismo na Região do Corede - Centro/RS e sua importância para o desenvolvimento regional. In: CONGRESSO BRASILEIRO DE ECONOMIA E SOCIOLOGIA RURAL, Foz do Iguaçu, 37. Anais... Foz do Iguaçu: SOBER, 1999.

VEIGA, L. Programa de Aquisição de Alimentos: Balanço e Perspectivas. Brasília: MDS, 2008.

VIANA, C.; VIEGAS, G. L. PAA - Evolução das Operações. In: Companhia Nacional de Abastecimento. Agricultura e Abastecimento Alimentar: Políticas Públicas e Mercado Agrícola. Brasília: CONAB, 2009, p. $146-154$.

WANDERLEY, M; N. B. A ruralidade no Brasil moderno. Por um pacto social pelo desenvolvimento rural. In: GIARRACCA, N. [org.]. Uma nueva ruralidad em América Latina? Buenos Aires, CLACSO/ ASDI, p. 31-44, 2001. 